\title{
Diagnostics and regulation of rheological characteristics for injection mortars by electromechanical sensors
}

\author{
Andrii Plugin ${ }^{1}$, Liudmyla Trykoz ${ }^{1, *}$, Oleksandr Donets $^{2}$, Andrii Nykytynskyj $^{1}$, and Anton Pluhin ${ }^{3}$ \\ ${ }^{1}$ Ukrainian State University of Railway Transport, Department of Building Materials, Constructions and Structures, Kharkiv, 61050, \\ Ukraine \\ ${ }^{2}$ O. M. Beketov National University of Urban Economy, Department of Electrical Transport, Kharkiv, 61002, Ukraine \\ ${ }^{3}$ National University of Radio Electronics, Department of Artificial Intelligence, Kharkiv, 61166, Ukraine
}

\begin{abstract}
In the article the diagnostic and regulation problems are considered for the rheological characteristics of mortars which are used for pumping into the interpipe gaps or cracks during repairing the pipelines, tunnels, and other objects. It is important to obtain the necessary mortar viscosity which allows providing a complete hole filling. For this aim the experimental dependencies have been determined between the injection mortar viscosity, the water-cement ratio, and the additives quantity in the mortars. According to the Poiseuille's flow law the theoretical dependencies have been obtained between the penetration depth of the injection mortar and viscosity under the different water-cement ratios. The said dependencies are a base during the development of the functioning algorithm the diagnostic and regulation system of the injection cement mortars rheological characteristics. The description of this functioning system is given. The mentioned system application allows increasing the cementation quality, corrosion resistance and durability of the repaired pipeline sections as well as decreasing of the work duration and labor costs.
\end{abstract}

\section{Introduction}

The injection technologies are widely spread for building and repairing of the infrastructure objects. These technologies include mortar injection - cementic, silicate, polymeric - into cracks, pores, seams, holes in building constructions, soil massives and/or between them. For example, the creation of a damp-proof layer against capillary rise by injection of chemical products is one of the most diffused methods, thanks to the relatively easy and cheap application [1]. In this case the hinder is overcoming capillary pressure in fine capillary pores. It requires an increase of the pumping pressure or the viscosity control.

The concrete permeability is becoming a serious problem for durability of hydraulic, water retaining and tunnel constructions due to the water influence or wet medium effect. To prolong service time and defence concrete and reinforced concrete constructions the various kinds of waterproofing are used: monolayer and multilayer ones, for cold and heated surfaces, with filler and without, as membrane or plaster. For each particular case it is necessary to come to a decision about the most effective method for the construction protection $[2,3]$. The fiberglass plastics, which are wrapped around pipes, give them greater strength and corrosion resistance [4]. One of the most effective repair methods of sewage pipelines damaged by microbiological corrosion is polymer covering or laminate $[5,6]$. The other way is a setting inside the pipeline a corrosion-resistant polymer inserts or steel sleeves $[7,8,9,10,11]$. These inserts are placed in the damaged part of the sewage pipeline. A formed intertube gap is filled by polymer or cement mortar which quality defines reliability and durability of the restored sector (Fig. 1). The mortar injection is realized under pressure which is produced by piston or pneumatic mortar pumps 4 through special injectorpackers 8 . The mortar is transported from pumps by hoses-mortartransporters.

The movement depth of the mortar by the hoses into crack, interpipe gap, and etc. as well as the cementation quality (filling gap continuity, density, strength, water impermeability of hardened mortar) are determined by mortar rheological parameters - shear yield stress and dynamic viscosity. These characteristics most depend on the water quantity in the mortar, the type and quantity of plasticizing additives - anion-active surfactants. That is why during the injection process it is necessary to carry out ongoing diagnostics of mortar rheological properties. If necessary the rheological properties should be corrected by the change of the water quantity and/or plasticizing additives. The mentioned diagnostics and correction are very difficult for automation, and a specialist usually performs them (Fig. 1, a). Nowadays this system should be automatized and computerized (Fig. 2). The development of such systems is an actual task.

The investigation aim is justification and development of the automatic system for diagnostics and correction of cement injection mortar rheological properties. 
a)

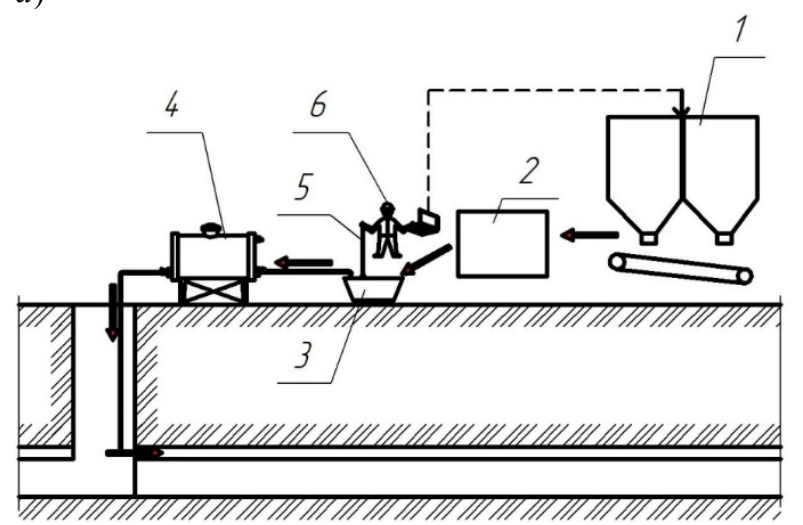

b)

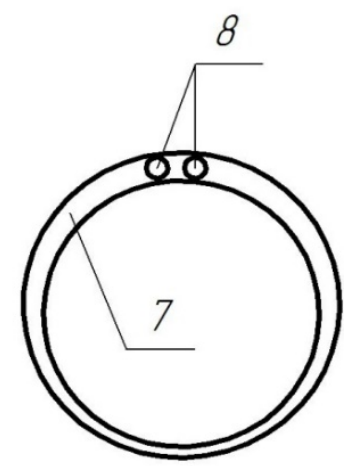

$\leftarrow$ mortar movement; ----- control signals; 1 material containers and dispensers; 2 - mortar mixer; 3 - mortar container; 4 - mortar pump; 5 device for rheological characteristic diagnostics; 6 - specialist; 7 - interpipe gap; 8 - injector-packers

Fig. 1. The cement mortar injection into the interpipe gap during the pipeline repairing by the insert method: $a$ - the technological injection scheme; $b$ - the injector setting scheme in the interpipe gap abut.

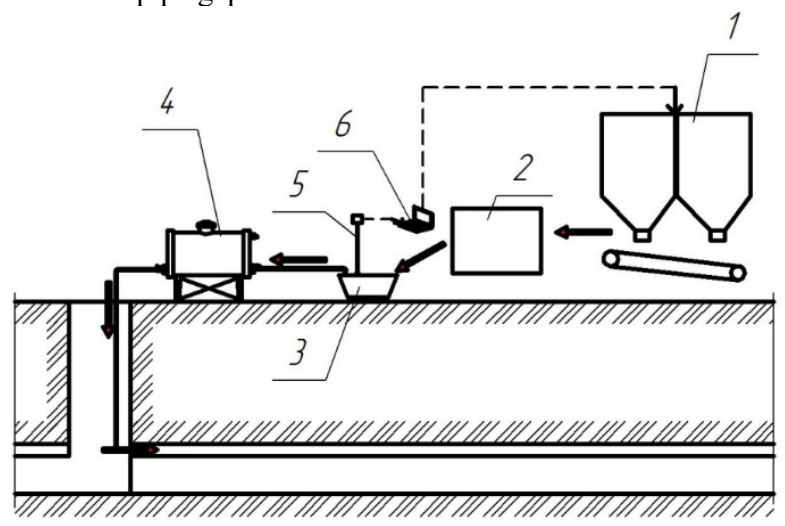

$\leftarrow$ mortar movement; ----- control signals; 1 material containers and dispensers; 2 - mortar mixer; 3 - mortar container; 4 - mortar pump; 5 automatic device for rheological characteristic diagnostics; 6 - system server for diagnostics and regulation of rheological characteristics

Fig. 2. The automatized system for diagnostics and regulation of rheological characteristics.

The research tasks are:
- choice and rationale of the method which is applicable to automatic system for diagnostics of injection mortar rheological properties;

- finding out the dependences applicable to automatic system between the permeation depth and the mortar viscosity needed for penetration ensuring into the whole interpipe gap;

- finding out the dependences applicable to automatic system between the water-cement ratio and the mortar viscosity with and without additive-superplasticizer;

- developing of the automatic system algorithm for diagnostics and regulation of cement injection mortar rheological properties.

\section{The choice of the diagnostic method for injection mortars rheological properties}

The choice has been carried out based on the analysis of the exist systems for automatic diagnostics and regulation of building materials technological parameters, in particular viscosity. Many researchers consider that rheological approach is more accurate and reliable compared with the traditional tests. Therefore, it is increasingly used in the different technological processes related to mixtures pumping. The studies on concrete pumpability combining different laboratory tools and linkage to rheology are conducted in $[12,13]$. The correlation between the rheological properties and the concrete pumpability are analyzed under various temperatures and time after mixing. As the pumpability characteristics the Bingham parameters and slippage resistance are chosen. The predictive capacity of the tribometer concerning the concrete pumpability is validated by measuring the discharge pressure. Also, it has been demonstrated that knowledge of the rheological properties of the lubrication layer is not sufficient to state whether the concrete is pumpable or not. Only a combination of rheological instruments makes the adequate description of concrete pumpability possible.

The yield stress and plastic viscosity values are necessary to ensure adequate filling ability and concrete stability for successful casting of prestressed elements. According to the results [14], it is recommended the concrete to have plastic viscosity within $30-130 \mathrm{~Pa} \cdot \mathrm{s}$ to provide its proper workability. Higher viscosity levels should be avoided due to its limitation in passing ability. Understanding of the rheological parameters is important for developing the quality control test methods. As it is shown in [15], the concrete rheology affects the surface quality. It is found out that the concrete mixtures with the yield stress lower than $25 \mathrm{~Pa}$ provide the best surface quality.

The science of rheology is increasingly used to describe the properties of fresh cement paste. Compared to standard workability tests, rheological properties allow carrying out more fundamental investigation, more precise phenomenological description of flow properties and serving as input for numerical simulations [16]. However, when the cement researchers use rheometers the results depend very much on choice of protocol and 
tested material. Unfortunately, there is no single procedure that works for all rheometers and there is no rheometer that works for all materials. Hence, the search of reliable way for rheological properties diagnostics is still being continued. For these aims researchers suggest the different methods for the rheological properties control: oscillatory rheology [17], ultrasonic spinning rheometry [18], rotational viscometer and dynamic shear rheometer [19].

The workability of mortar and concrete could be evaluated in terms of their flowability and deformability during pumping and filling operations. However, there is no rheological criterion yet upon which the dynamic stability could be evaluated [20]. To predict and control the concrete behavior numerous studies are performed in [21]. The results demonstrate that there is no clear relationship between flow resistance and piston pressure. By contrast, fairly good statistical correlations exist between torque viscosity and piston pump pressure. Therefore, the torque can be the rheological parameter for the mortar and concrete workability. Based on this, the special sensors can be acceptable for diagnostics of injection mortar rheological properties. These sensors consist of two parts - mechanical and electrical. The mechanical part contacts with mortar and electrical one is placed outside mortar or isolated from it. The sensor can be proposed as such device in [22] and in which the electric motor translationally moves a spherical spindle inside the mortar. This sensor is based on amperage conversion on the motor shaft to the rheological characteristics with the usage of dependencies determined earlier. But for the such system the dependencies have not still been established between the mortar rheological properties and the mortar viscosity which are necessary for penetration ensuring into the whole interpipe gap as well as the dependencies are not established between the mortar penetration depth into gaps, cracks, seams, and the mortar rheological properties. The influence the water quantity in the mortar and quantity of plasticizing additives on the mortar rheological properties is not established either.

\section{Theoretical bases and experimental studies}

To define the above mentioned dependencies a flow process of cement mortar (suspension) as a waterdispersion system is analyzed in the annular gap (slotted gap for crack) with thickness $a$. The mortar flows in the annular gap (crack) under pumping pressure $p$ while an external pressure opposes it. The external pressure is formed by the ground water pressure or water pressure $p_{h}$ which remains after washing of the interpipe gap. Also the external pressure includes the pressure $p_{f}$ formed by friction force $F$ along gap walls. As a result of pressure equalization, a stationary flow with speed $v$ is installed. Since the penetration is performed at depth $l$ during injection time $\tau$ it can be taken

$$
v=l / \tau, \mathrm{m} / \mathrm{sec} .
$$

In case of a big gap thickness $a$ and filling gap by water, the effects considering meniscus formation can be neglected. According to the Poiseuille's flow law the internal friction force equals

$$
F=\eta S_{s} v / \delta
$$

where $\eta$ is the effective dynamic viscosity of the mortar, $\mathrm{s} / \mathrm{m}^{2} ; v / \delta$ is the mortar flow rate gradient, $1 / \mathrm{s} ; \delta$ is the mortar near-wall layer thickness in which water speed is changed from 0 to $v, \mathrm{~m} ; S_{s}$ is the gap surface area, $\mathrm{m}^{2}$

$$
S_{s}=[\pi d+\pi(d+a)] l=\pi l(2 d+a),
$$

where $d$ is internal diameter of the annular gap, $\mathrm{m}$.

After substitution (3) in (2) it is obtained

$$
P_{f}=\frac{F}{S}=\frac{\eta S_{S} v}{S \delta}=\frac{\eta v \pi l(2 d+a)}{\pi h(d+0.5 a) \delta}=\frac{2 \eta v l}{a \delta},
$$

where $S$ is an annular gap surface area, $\mathrm{m}^{2}$

$$
S=\pi(d+0.5 a) a=\pi a(d+0.5 a) .
$$

The stationary flow is installed under condition

$$
p=p_{h}+p_{f}
$$

Having substituted (4), and then (1) in (6), it is obtained

$$
p-p_{h}=\frac{2 \eta v l}{a \delta}=\frac{2 \eta l^{2}}{a \delta \tau} .
$$

After transformation (7), the mortar injection depth dependence in the gap from the gap thickness $a$ and a mortar viscosity $\eta$ is obtained

$$
l=\sqrt{\frac{\left(p-p_{h}\right) a \delta \tau}{2 \eta}}
$$

and the viscosity dependence $\eta$ which is required for the penetration depth ensuring $l$ in the gap thickness $a$

$$
\eta=\frac{\left(p-p_{h}\right) a \delta \tau}{2 L^{2}} .
$$

Investigate the dependence of the mortar penetration depth $l(8)$ as a function of the interpipe gap thickness (crack disclosing) $a$. The bounding conditions are the quantity characteristics of the reviewed constructions and technologies: the repair section length - less than $100 \mathrm{~m}$; the annular gap thickness $-0 \div 20 \mathrm{~mm}$ in a bench flume and less than $100 \mathrm{~mm}$ in an arch; the proof-test pressure less than $0.16 \mathrm{MPa}$ (it is limited in a pump possibility and pipe strength); the proof-test pressure time - about 10 min; the mortar working life - bigger than an hour (it is limited in an injection duration).

For calculations on (9) the hydrostatic pressure of water which is displaced during proof-test pressing is taken equal for the case when water ground level is higher at $3 \mathrm{~m}$ from a sewer pipe. So, the water column height $h=3 \mathrm{~m}$, and the hydrostatic pressure equals

$$
p_{h}=\rho \cdot g \cdot h=1000 \cdot 9,81 \cdot 3 \approx 30000 \mathrm{~Pa},
$$


where $\rho$ is the water density, $1000 \mathrm{~kg} / \mathrm{m}^{3} ; g$ is the gravity acceleration, $9.81 \mathrm{~m} / \mathrm{s}^{2}$.

The proof-test pressure $p$ is accepted equal $160000 \mathrm{~Pa}$, the proof-test pressure time $\tau$ is assumed to be $600 \mathrm{~s}$. The mortar near-wall layer thickness $\delta$ in which water speed is changed from 0 to $v$ is assumed to be $2.5 \cdot 10^{-5} \mathrm{~m}$ for the mortar without additives, and $0.8 \cdot 10^{-6} \mathrm{~m}$ for the mortar with additives $[23,24]$. After appropriate substitutions the equation (8) takes the form for the mortar without and with additives, accordingly

$$
l=31.2 \cdot(a / \eta)^{0.5} ; l=55.9 \cdot(a / \eta)^{0.5} .
$$

The hardened mortar should possess water impermeability which is not less than concrete impermeability of the pipes used for free-flow collectors building. The concrete water impermeability of such constructions should be W4 according the National Standard [25]. The number "4" means the pressure in atm under which the water penetration does not occur after keeping the concrete samples during determined time under pressure. For concrete the mentioned impermeability class is provided with water-cement ratio $(\mathrm{W} / \mathrm{C})$ less than 0.6 . Since the concrete permeability is mainly depended on the cement stone properties, it is necessary also to accept $\mathrm{W} / \mathrm{C}$ less than 0.6 for the injection mortar. The impact degree of an operational medium to the sewer collector is highly aggressive chemical environment XA3 according to $[25,26]$ taking into account $\mathrm{pH}$ value. Under this condition the concrete water impermeability class should be increased to W8 which is provided with $\mathrm{W} / \mathrm{C}$ less than 0.45 . Therefore, the mortar $\mathrm{W} / \mathrm{C}$ value for the interpipe gap cementation should be taken not more than 0.45 but it is advisable even less based on the conditions ensuring the water impermeability and corrosion resistance as well as durability of the collector constructions. Such W/C ratios can be achieved only with the usage of cementitious mortar with additive-superplasticizers based on the conditions mortar pumping by pumps.

Define the experimental dependencies between dynamic viscosity and $\mathrm{W} / \mathrm{C}$ ratio. The dynamic viscosity values have been determined with the usage of the rotational viscometer. For studies the cement-water suspension has been performed with different watercement ratios and addition of the superplasticizer (sodium salt of polymethylene poly-naphthalene sulfonic acid). The experimental results are given on the Fig. 3 .

For calculations on the formula (10) the mortar dynamic viscosities $\eta$ are taken according to Fig. 3:

- for the mortar without additives with $\mathrm{W} / \mathrm{C}=0.6-$ $0.125 \mathrm{~Pa} \cdot \mathrm{s}$, with $\mathrm{W} / \mathrm{C}=0.45-0.27 \mathrm{~Pa} \cdot \mathrm{s}$, with $\mathrm{W} / \mathrm{C}=0.35$ $-2.33 \mathrm{~Pa} \cdot \mathrm{s}$;

- for the mortar with additive-superplasticizer with $\mathrm{W} / \mathrm{C}=0,6-0,002 \mathrm{~Pa} \cdot \mathrm{s}$, with $\mathrm{W} / \mathrm{C}=0.45-0.01 \mathrm{~Pa} \cdot \mathrm{s}$, with $\mathrm{W} / \mathrm{C}=0.35-0.061 \mathrm{~Pa} \cdot \mathrm{s}$.

Graphic presentations of the calculations by formula (10) are given on Fig. 4.

As it follows from Fig. 4 the cement mortars without additives with $\mathrm{W} / \mathrm{C}=0.45 \div 0.6$ do not penetrate into the interpipe gap for the distance more than $40 \mathrm{~m}$.

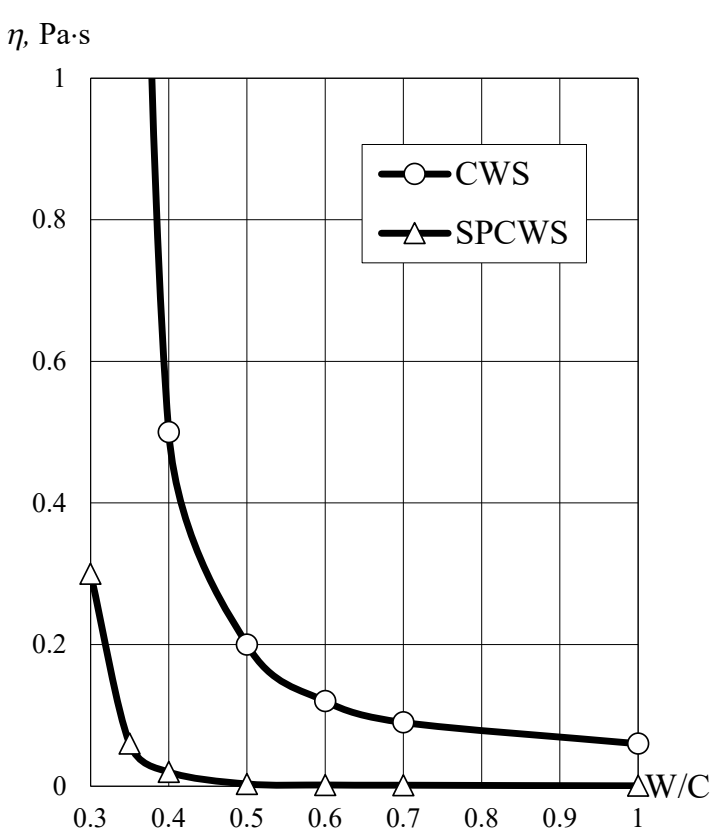

$C W S$ - ordinary mortar (cement-water suspension); $S P C W S$ - mortar with additive-superplasticizer (superplasticized cement-water suspension)

Fig. 3. The dependence between the cement mortar dynamic viscosity $\eta$ and the water-cement ratio $W / C$.
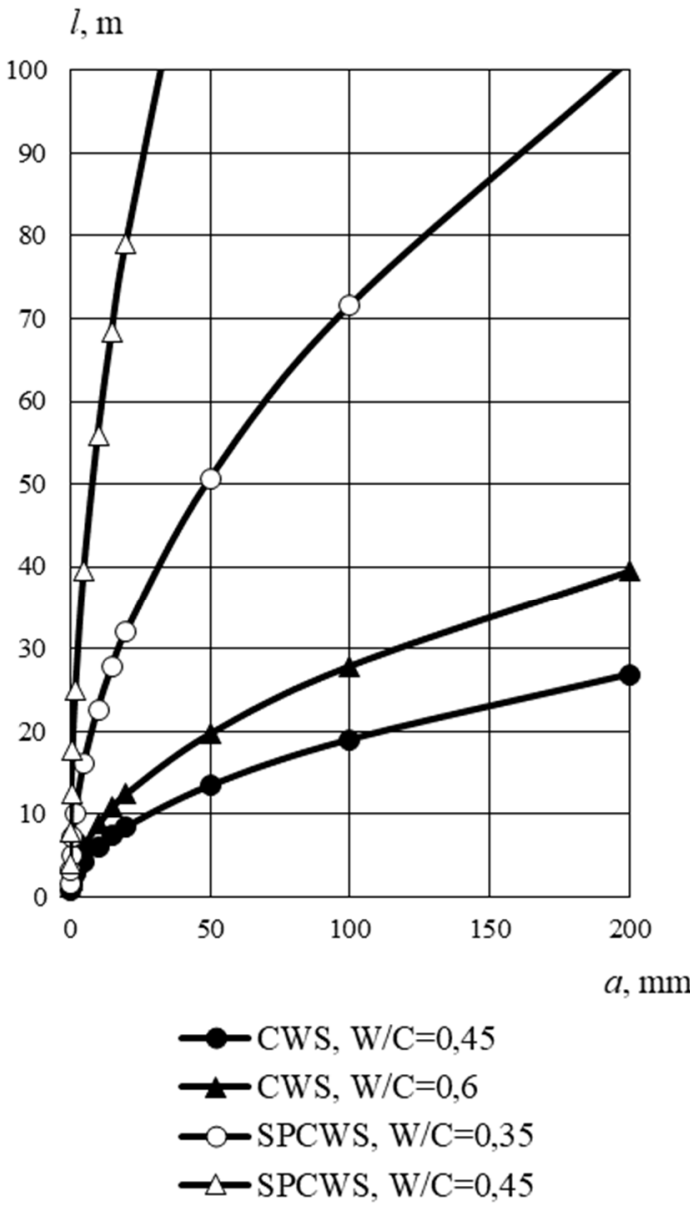

Fig. 4. The dependence between the penetration depth $l$ of the injection mortars and the interpipe gap width (crack) $a$. 
The mortars with additive-superplasticizers with $\mathrm{W} / \mathrm{C}=0.35 \div 0.45$ penetrate for the distance to $100 \mathrm{~m}$. Such W/C ratios provide the necessary water impermeability and corrosion resistance of a cement stone. Thereby the cement mortar with W/C not more 0.45 should be applied for cementation of the interpipe gap during a new pipeline arrangement inside damaged sewage collectors. When the repair section length is not more than $20 \mathrm{~m}$ the mortar without additives is suitable for the usage. If the length is from $20 \mathrm{~m}$ to $100 \mathrm{~m}$ the usage of additive-superplasticizer is required.

To sum, the dependence (9) between the required mortar viscosity and the interpipe gap width as well as the repair section length (penetration depth) is applicable for the automatic diagnostic system. The dependence the $\mathrm{W} / \mathrm{C}$ ratio as a function the required viscosity can be obtained after an approximation of the dependencies given on Fig. 4.

\section{Algorithm development for automatic system}

Among the automatic systems for diagnostics and regulation of the building object parameters there is a system which allows diagnosing the wet state and stability of the ground massive [27]. This system uses the coaxial sensors with capillary backfill contacting with ground. The bigger soil wet the bigger backfill wet. The sensor measures electrical resistance or electrical capacitance of the backfill. Then these values are digitized and transformed to the ground wetness parameter using the analytical dependencies. The system informs an operator about the moisture amount. If it is provided for, the system generates control signal for actuating mechanisms which perform draining or fixing the ground. If suchlike mechanisms are absent the system recommends to the specialist to choose certain methods for draining or fixing the ground. However, this system is automatic in part and expert partially. Besides the used sensors are suitable for not too large quantities of wetness for dispersed material such as soil. These values can be significantly less than the water content of the injection mortar. Also, such sensors are not applicable in case of an addition of the hardening accelerators-electrolytes into the injection mortar.

The magnitude of the mechanical effort to move the mobile part of the device to measure the shear stress can be converted into an electrical signal. For this research, an electromechanical device ES-1 (Fig. 5) was developed in which the measuring spindle is a sphere which is driven by the electric drive and moves at a constant speed. The measuring scale is an ammeter, which shows the strength of the current on the shaft of the electric motor and which is pre-set with the desired workability index of the mortar. A control signal is taken from the shaft of the electric motor, for the automated control system to prepare the building mortar. The current strength can be used as the conventional viscosity of the mortar, and the dependence can be applied to automatic maintenance of water content and given technological characteristics.

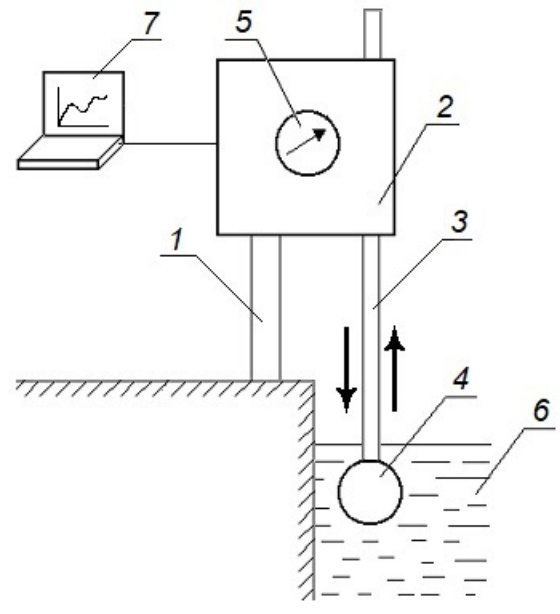

Fig. 5. Electromechanical device for determining the rheological and technological characteristics of building mortars: 1 - tripod; 2 - electric drive; 3 -rod; 4 - spherical spindle; 5 -ammeter; 6 - building mortar; 7 - computer.

An algorithm of the developed automatic system for diagnostics and regulation of rheological properties for the cement injection mortars is given on Fig. 6. The algorithm functions in the following way. The operator, who performs the system work, with the help of statement 2 inputs the values of the length $\mathrm{L}$, the interpipe gap width $\delta$, the maximum permissible deviation of mortar viscosity $\Delta \eta_{\max }$, the maximum permissible water content in mortar $W_{\max }$, the interpipe gap volume $V_{\max }$ including hollows and cavities in the damaged places, the mortar mixer volume of discrete action $v$. Statement 3 calculates the permissible mortar viscosity $\eta$ depending on $L$ and $\delta$, and operator 4 counts the water consumption $W$ depending on $\eta$.

Statement 5 assigns the value 0 for number of the mortar preparation cycle $i$. Statement 6 compares the water consumption $W$ with the maximum permissible water content in mortar $W_{\max }$. If $W>W_{\max }$, statement 7 assigns $W$ the value $W_{\max }$, and statement 8 calculates the additive-superplasticizer consumption $A$ depending on $W_{\max }$ and the required mortar viscosity $\eta$. If $W$ is not bigger than $W_{\max }$, statement 9 assigns the value 0 for the additive-superplasticizer consumption $A$. Statement 10 increases the number of the mortar preparation cycle $i$ by 1 , and statement 11 outputs the number of the mortar preparation cycle $i$, the consumption of water $W$ and additive-superplasticizer $A$, the required viscosity $\eta$ for information of the specialist, as well as transmits the value $W$ and $A$ to actuating mechanisms of batchers.

The batchers dose the mortar components into the mortar mixer that prepares the mortar. After that the mortar viscosity diagnosing is performed by the electric drive-ball sensor, and the mortar is pumped by the pump through the mortar conduit into the gap. Amperage $I$ from the sensor of the motor shaft is digitized with the usage of a converter and input in the algorithm by statement 12 .

Statement 13 converts amperage to the mortar viscosity $\eta_{i}$. Statement 14 counts the mortar total amount $V$ which entered into the gap after $i$-th cycle, and statement 15 compares the obtained value $V$ with maximal volume 
of the interpipe gap $V_{\max }$. If $V<V_{\max }$ statement 16 calculates the deviation made by the diagnostic system, the viscosity value $\eta_{i}$ from the demanded viscosity $\eta$.

From an operator

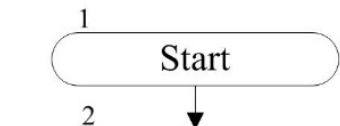

2
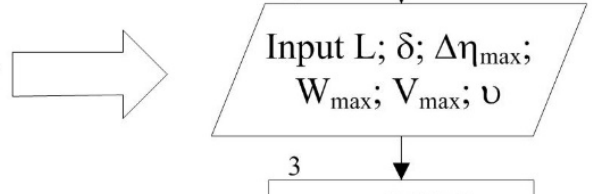

$\eta=\mathrm{f}(\delta ; \mathrm{L})$

4

$\mathrm{W}=\mathrm{f}(\eta)$

$\mathrm{i}=0$

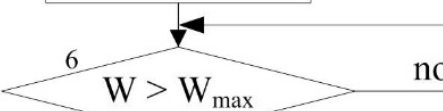

$7 \quad \nabla$ yes

$\mathrm{W}=\mathrm{W}_{\max }$

8

$\mathrm{A}=\mathrm{f}\left(\mathrm{W}_{\max } ; \eta\right)$

10

$\mathrm{i}=\mathrm{i}+1$

To an operator and actuating mechanisms

11

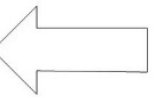

Output i; W; A; $\eta$

From a diagnostic system

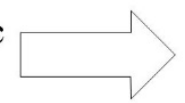
12

12

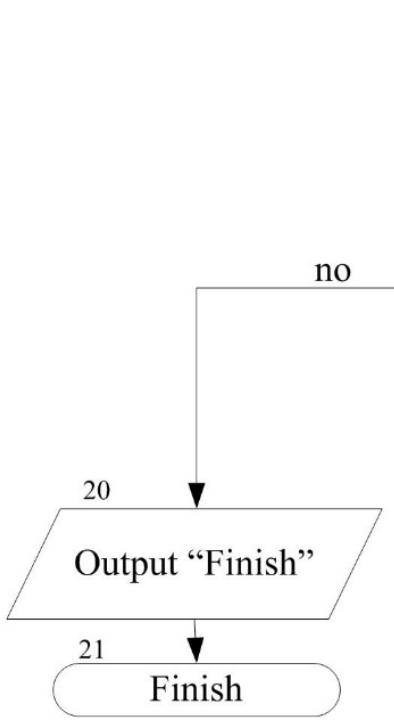

Input I

13

$$
\eta_{\mathrm{J}}=\mathrm{f}(\mathrm{J})
$$

14

$\mathrm{V}=\mathrm{iv}$
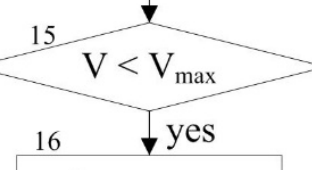

$$
\Delta \eta=\eta_{I}-\eta
$$

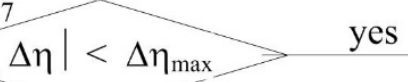

$$
\begin{aligned}
& 18 \quad \nabla \text { no } \\
& \Delta \mathrm{W}=\mathrm{f}(\Delta \eta) \\
& 19 \quad \downarrow \\
& \mathrm{W}=\mathrm{W}+\Delta \mathrm{W}
\end{aligned}
$$

Fig. 6. Functioning algorithm of the diagnostic and regulation system of the injection mortars rheological characteristics. 
Statement 17 compares the absolute value of the viscosity deviation $|\Delta \eta|$ which is defined by statement 16 with the maximum permissible value $\Delta \eta_{\max }$. If $|\Delta \eta|<\Delta \eta_{\max }$ statement 17 returns the executing programme to statement 10 . If $|\Delta \eta|$ is not less than $\Delta \eta_{\max }$ statement 18 calculates the correction of the water consumption $\Delta W$ depending on the viscosity deviation $\Delta \eta$, and statement 19 counts the new corrected water consumption $W$ and returns the executing programme to statement 6. If $V$ is not less than $V_{\max }$ statement 20 reports about the work completion, and statement 21 ends it.

\section{Conclusions}

1. The electromechanical sensor is chosen for the automatic diagnostics and regulation system of the rheological characteristics for the injection mortars which are used for repairing the sewage pipes by the insert method. The sensor mechanical part contacts with the mortar but the electric part is placed outside the mortar. An electric signal - amperage - is removed from the motor shaft which translationally moves a spherical spindle inside the mortar. After digitizing the amperage is transformed to the mortar viscosity value.

2. The dependencies between the mortar viscosity, the penetration depth, and the water-cement ratio of the cement mortar both without the additives and with the additives-superplacticizer are received. These dependencies are applicable for the automatic diagnostic and regulation system of the rheological characteristics for the injection cement mortars.3. Functioning algorithm of the automatic diagnostic and regulation system of the injection mortars rheological properties is developed for cementation of the interpipe gap during repairing the sewage pipes by the insert method. The system application allows increasing of the cementation quality, corrosion resistance and durability of the repaired pipeline section as well as decreasing the work duration and labor costs.

\section{References}

1. A. Hacquebord, B. Lubelli, R. Robvan Hees, T.Nijland, Evaluation of Spreading and Effectiveness of Injection Products against Rising Damp in Mortar. Proc. Chem. 8, 139-149 (2013). doi:10.1016/j.proche.2013.03.019

2. K.-S. Kwak, S.-J. Ma, S.-M. Choi, S.-K. Oh, Property Analysis of Waterproofing and Corrosion-Resistant Performance in Concrete Water Supply Facilities. J. Kor. Rec. Constr. Res. Inst. 3(2), 122-131 (2015). doi:10.14190/jrcr.2015.3.2.122

3. A. Margaryan, Armenian and European Methods of Tunnel Waterproofing. Int. J. Res. Chem., Met. and Civ. Eng. 3(1), 7-9 (2016). doi:10.15242/ijrcmce.ae0116208

4. L. Trykoz, S. Kamchatnaya, O. Pustovoitova, A. Atynian, Reinforcement of composite pipelines for multipurpose transportation. Tran. Prob. 13(1), 6979 (2018). doi:10.21307/tp.2018.13.1.7
5. P. Chindaprasirt, U. Rattanasak, Improvement of durability of cement pipe with high calcium fly ash geopolymer covering. Constr. and Build. Mat. 112, 956-961 doi:10.1016/j.conbuildmat.2016.03.023

(2016).

6. A.B. Pridmore, R.P. Ojdrovic, in Rehabilitation of Pipelines Using Fiber-reinforced Polymer (FRP) Composites (Elsevier BV, 2015), pp. 17-38. doi:10.1016/b978-0-85709-684-5.00002-3

7. L. Aguiar, A. Pridmore, M. Geraghty, in Pipelines 2015 (American Society of Civil Engineers ASCE, 2015). doi:10.1061/9780784479360.115.

8. W.A. Bruce, in Rehabilitation of Pipelines Using Fiber-reinforced Polymer (FRP) Composites (Elsevier BV, 2015), pp. 61-78. doi:10.1016/B9780-85709-684-5.00004-7

9. M. Ehsani, in Rehabilitation of Pipelines Using Fiber-reinforced Polymer (FRP) Composites (Elsevier BV, 2015), pp. 39-59. doi:10.1016/B9780-85709-684-5.00003-5

10. A.B. Pridmore, R.P. Ojdrovic, in Rehabilitation of Pipelines Using Fiber-reinforced Polymer (FRP) Composites (Elsevier BV, 2015), pp. 1-15. doi:10.1016/B978-0-85709-684-5.00001-1

11. C.S. Sirimanna, A.C. Manalo, W. Karunasena, S. Banerjee, L. McGarva, in Rehabilitation of Pipelines Using Fiber-reinforced Polymer (FRP) Composites (Elsevier BV, 2015), pp. 267-285. doi:10.1016/B978-0-85709-684-5.00013-8

12. E. Secrieru, V. Mechtcherine, C. Schröfl, D. Borin, Study on concrete pumpability combining different laboratory tools and linkage to rheology. Const. and Build. Mat. 144, 451-461 (2017). doi:10.1016/j.conbuildmat.2017.03.199

13. E. Secrieru, S. Fataei, C. Schröfl, V. Mechtcherine, Rheological characterisation and prediction of pumpability of strain-hardening cement-basedcomposites (SHCC) with and without addition of superabsorbent polymers (SAP) at various temperatures. Const. and Build. Mat. 112, 581-594 (2016). doi:10.1016/j.conbuildmat.2016.02.161

14. W.-J. Long, K.H. Khayat, A. Yahia, F. Xing, Rheological approach in proportioning and evaluating prestressed self-consolidating concrete. Cem. and Conc. Comp. 82, 105-116 (2017). doi:10.1016/j.cemconcomp.2017.05.008

15. W.A. Megid, K.H. Khayat, Effect of concrete rheological properties on quality of formed surfaces cast with self-consolidating concrete and superworkable concrete. Cem. and Conc. Comp. 93, 75-84 doi:10.1016/j.cemconcomp.2018.06.016

(2018).

16. D. Feys, R. Cepuritis, S. Jacobsen, K. Lesage, E. Secrieru, A. Yahia, Measuring Rheological Properties of Cement Pastes: Most common Techniques, Procedures and Challenges. RILEM Tech. Let. 2, 129-135 (2017), https://letters.rilem.net/index.php/rilem/article/view/43. Accessed 25 Mar 2019 
17. R. Mercado, L. Fuentes, Measure of asphalt emulsions stability by oscillatory rheology. Const. and Build. Mat. 155, 838-845 (2017). doi:10.1016/j.conbuildmat.2017.08.095

18. T. Yoshida, Y. Tasaka, Y. Murai, Rheological evaluation of complex fluids using ultrasonic spinning rheometry in an open container. J. Rheol. 61, 537-549 (2017). doi:10.1122/1.4980852

19. Y.J. Kim, B.Y. Cho, S.J. Lee, J. Hu, J.W. Wilde, Investigation of Rheological Properties of Blended Cement Pastes Using Rotational Viscometer and Dynamic Shear Rheometer. Advances in Materials Science and Engineering, 6303681 (2018). doi:10.1155/2018/6303681

20. A.Y. Abebe, L. Lohaus, Rheological characterization of the structural breakdown process to analyze the stability of flowable mortars under vibration. Const. and Build. Mat. 131, 517-525 (2017). doi:10.1016/j.conbuildmat.2016.11.102

21. Kyong-KuYun, Pangil Choi, Jung HeumYeon, Correlating rheological properties to the pumpability and shootability of wet-mix shotcrete mixtures. Const. and Build. Mat. 98, 884-891 (2015). doi:10.1016/j.conbuildmat.2015.09.004

22. O.V. Donets, A.A. Plugin, V.I. Babushkin, D.M. Titov, V.O. Renyov, UA Patent 55610, 15 Apr 2003

23. Y. Takagi, K. Takasu, H. Koyamada, H. Suyama, A basic study on fluid prediction of mortar with various powders. Int. J. of GEOMATE 14(4), 146-150 (2018). doi:10.21660/2018.42.3548

24. R. Zhang, D.K. Panesar, New approach to calculate water film thickness and the correlation to the rheology of mortar and concrete containing reactive MgO. Const. and Build. Mat. 150, 892-902 (2017). doi:10.1016/j.conbuildmat.2017.05.218

25. DSTU B V.2.6-145:2010 Konstruktsii budynkiv $i$ sporud. Zakhyst betonnykh $i$ zalizobetonnykh konstruktsii vid korozii. Zahalni tekhnichni vymohy (Buildings and facilities structures. Corrosion protection for concrete and reinforced concrete srtuctures. General technical requirements). (Minregiobud of Ukraine, Kyiv, 2010)

26. EN 206-1:2000/A1:2004 Concrete - Part 1: Specification, performance, production and conformity (European Committee for Standardization, 2004)

27. A. Plugin, L. Trykoz, O. Herasymenko, A. Pluhin, V. Konev, Independent diagnostic computer systems with the ability to restore operational characteristics of construction facilities. Diag. 19(2), 11-21 (2018). doi:10.29354/diag/83009. 